\title{
Development of pre-time intersection isolated signal using a fuzzy logic model
}

\author{
Moch. D. Studyana ${ }^{1, *}$, Ade Sjafruddin ${ }^{2}$, Iwan P. Kusumantoro ${ }^{3}$, and Yudi Soeharyadi ${ }^{4}$ \\ ${ }^{1}$ Doctoral Study Program of Civil Engineering, Faculty of Civil and Evironmental Engineering, Institut Teknologi Bandung, Bandung, \\ Indonesia \\ ${ }^{2}$ Transportation Engineering Research Group, Faculty of Civil and Evironmental Engineering, Institut Teknologi Bandung, Bandung, \\ Indonesia \\ ${ }^{3}$ Regional and Urban Infrastructure System Research Group, School of Architecture, Planning and Policy Development, Institut \\ Teknologi Bandung, Bandung, Indonesia \\ ${ }^{4}$ Analysis and Geometry Research Group, Department of Civil Mathematics, Faculty of Mathematics and Natural Sciences, Institut \\ Teknologi Bandung, Bandung, Indonesia
}

\begin{abstract}
We investigate the development of pre-time signal intersection operating systems for isolated intersections using Fuzzy Logic models. The traffic signal system setting in Indonesia has been using the Indonesia Road Capacity Manual model 1997, for example it is installed at the intersection in large cities in Indonesia. The development of the Fuzzy Logic model is focused on improving the performance of the signaled intersection, using a combination of numerical variable analysis used by IRCM 1997, and the linguistic or traffic behavior variable as the basis of the Fuzzy Logic model study. The combination of the two variables in the Fuzzy Logic model analysis is expected to improve the intersection performance. The Fuzzy Logic model process involves the Membership Function theory as the basis for the confidence level of the traffic variable to be surveyed, and the Fuzzy Inference Engine to measure the choice of combinations of variables that will be selected to make the best performance of the intersection. The geometric of intersection must be control as it involves the input of research data, especially on the condition of the intersection legs and markers of motor cycle-special stopping places, which is a potential of a traffic violation by traveller. The model is verified with fuzzified data from 2017 traffic research survey in Bandung. As an illustration of the majority of intersection setting with an isolated pretime operating system, there are 60 intersection points or $85 \%$ of the total 71 intersections available. This would be a potentially major problem when performance improvements is not carried out. The final analysis shows that the number of vehicles queues decreases while the traffic flows passing through the intersection increases, therefore fuzzy logic model is expected to contribute and to give alternative handling for intersection performance with pre-time operational.
\end{abstract}

\section{Introduction}

The use of signaling intersection settings based on fixed time or pre-time is very popular and almost all intersections in Indonesia use the majority of the system. The signal timing process involves inputting traffic flow data in controlling the intersection [1]. Traffic flow is a quantitative data input obtained by conducting a survey at the intersection that will be studied continuous and left and right turn current movement will be a basic reference for controlling phase analysis at each intersection approach to avoid conflicts that occur between vehicles at the intersection. The phase that occurs is a process of electrically displacing the signal time from the movement of the vehicle that will pass through the intersection, based on the vehicle conflict control on each intersection approach is opposite or unopposite [2]. The main focus of pre-time signal control is setting the fixed time on each approach for a moving vehicle is not affected by the fluctuations of traffic flow. The saturation level of traffic volume will be regulated through cycle times so that the movement of vehicles can still pass through the intersection smoothly and savely. Cycle time is the basis for consideration in evaluating queue length. There is often a loss time affecting the arrival times of vehicles coming at the intersection mouth [3]. Signal control with green phase and red phase traffic light input is evaluated with two stage fuzzy signal control, that is, with the first step controlling the judgment status, and second stage in the form of a decision which results in the extension of green time [4]. An isolated intersection is an important element in the overall traffic control system within a city. In this paper we consider an approach in modeling traffic flow of an isolated intersection, based on a traffic flow,

\footnotetext{
*Corresponding author: study_lembur@yahoo.co.id
} 
queue, Left Turn On Red (LTOR) and Motorcycles Stop Room (MSR) in analysis. Research, often does not include all variables, or it they are included, limited samples which can be obtained are not enough to evaluate the impact of various parameters [3]. The installation of appropriate and efficient traffic signals can produce optimal performance, such as reduced number of vehicle queues on each approach, minimizing the delay time for vehicles that pass the intersection and the on increase intersection capacity [5]. The signal installation is generally carried out separately from other intersections which are isolated. Because there are differences in characteristics at each intersection in term of the amount of traffic flow, queue length, waiting time, cycle time and the number of violations that occur. Pre-time signal operation is carried out by setting the fixed signal time that is the operation is set for cycle length, green time and interval change. The signals are on by setting a fixed cycle time in a fixed pattern that is each cycle has a predetermined length of time and phase permanent [6]. The development of a traffic control system with a fuzzy logic model is the use of traffic light control involving the input of linguistic variables such as high flow, medium and low. The queues long, medium and short of course this is in line with human thinking in general and easily understood by computer algorithms [7]. The fuzy logic model can control for a four-way intersection for mixed traffic including a high proportion of motor cycles. As well as the traffic control strategy by using fuzzy logic control components. Like that the fuzzifier, fuzzy rule base formulated by human experts, the fuzzy inference engine and the defuzzfier [8]. Development of intersection arrangements began to be introduced with the development of intersection arrangements began to be introduced with development of traffic control systems using traffic lights has been achieved since the first traffic controller was installed in London in 1868 and starting from an isolated signalized intersection. The first green wave was realized in Salt Lake City in 1918, and the first intersection traffic control was introduced in Toronto in 1960. Traffic control equipment has followed technology development. At the very beginning, traffic control had been performed by electromechanical devices. Then, semiconductor-based controllers were introduced, and nowadays microprocessor-based controllers are used in traffic control systems. The development of traffic control systems, especially since 1960, has led to introduction of other equipment in traffic control systems, such as computers, telecommunication devices, vehicle detectors, etc [3]. As for in Indonesia the use of intersection traffic signal control began to be used since 1990 until now and still uses conventional models [1]. Of course this needs to be modified and changed, in this paper the development of fuzzy logic models will be tried to be applied to the junction condition of four arms with the pre-time settings for isolated intersections. The process of developing control of traffic signals on a fuzzy system begins with inputting the initial data in the form of qualitative data or linguistics as data updates, and combined with quantitative data input. The second input combination of the data be treated in the fuzzifier process to make at the membership function data classification according to the data input criteria. Functionally the data is divided into several groups which will produced the lower and upper limits of the fuzzy system and according to the field conditions at the intersection. The next step is included in the fuzzy inference engine for each combination that emerges, in line with the max-or theory which is reinforced by fuzzy languages and fuzzy set theory [9]. To get a combination of conclusions on incoming and outgoing data variables is done by a fuzzy process rule base based on the if-and-then pattern and, the final step is the de-fuzzifier process as a result of the development of the signalized intersection pre-time from the fuzzy logic model. Optimization of isolated time signals with the multi-variables is functionally converted into a single objective function, namely the optimum efective green time and flow capacity [10]. The control of traffic flow control at the intersection is usually done by installing red, yellow and green signal lights. The length of time it lights up is very helpful especially in terms of reducing the number of vehicles queuing at each intersection approach and can avoid conflicts between vehicles that have the potential to crash, as well as measure the performance of signalized intersections [1]. So that to avoid traffic jams due to the presence of a opposite direction traffic flow conflict, the intersection capacity can be maintained as efficiently as possible and does not cause very long queues. The advantage of installing traffic lights can provide clear rules for motorists or pedestrians when passing intersections. Can reduce the level of accidents caused by conflicts between vehicles or with pedestrians who cross. But often when the traffic flow conditions are reduced or in a swift condition. The vehicle is moving at high speed so that it has the potential to cause traffic violations and not give the other traveller the right to run according to the time the lights are on. It turns out that the existence of the operation of the signal is very instrumental in terms of devided the splitting movement from straight and right turn of traffic, or to movements coming from intersecting paths directly or major conflicts [1]. The analysis of the setting of isolated intersection lights can be done with the traffic control system approach using a fuzzy logic model that is the use of traffic light control involving quantitative and qualitative variable inputs. Where fuzzy logic is an external continuous concept with a subjective and objective combination of all variable involved. The definition of using fuzzy logic control is the use of linguistic "words", for example "dense", "little", "long" which is in line with the human mind [7]. In general, linguistic forms in transportation, especially signalized intersections are often unknown because often the parameters are not clear. Like there are two different interpretations or ambiguity, uncertainty, unprecision or subjectinty. This condition is usually very confusing to the driver in terms of making decisions, including for traveller or operators in the field. so it turns out that linguistic information is very subjective because it involves knowledge perceptions or decision makers. During this time intersection analysis often uses numerical or quantitative variable using traffic flow theory. It turns out that the reality of the traffic variables can be qualitative or linguistic, so that the handling needs to be done using a fuzzy logic theory. Discussion of the 
research based on qualitative data has been developed by several transportation experts with the application of fuzzy theory [5]. Suggesting the idea of using fuzzy theory to control the addition of green time based on emergency car time intervalsa when the intersection passes, including setting green time (on /off) for the pedestrian when the ambulance passes. Of course optimization is done so that the fixed signaled intersection can still normal traffic flow, that is unsaturation flow, and traffic lights always function properly to regulate traffic movements. The intersection performance measures can be done by controlling or modifying the existing conditions of traffic lights and evaluating traffic behavior when passing through intersections, by evaluating the existing signals using conventional methods and developing controls with fuzzy logic models.

\section{Experiment}

The data was gathered in the period April - May, 2016 by taking the field data at the isolated signal intersection Cibaduyut Street - Soekarno Hatta Street located in the city of Bandung.

\subsection{Design criteria and constraints}

The number of isolated and pre-time signal intersections has 61 intersections throughout the city of Bandung. The sampling method was carried out using the two stage cluster sampling method and geometric intersection criteria must be met such as the available left turn lane directly with intersection leg, there are Motorcycles Stop Room markings (MSR) including zebra crossing. Finally, those who meet these conditions obtained four intersections namely jl. Pasteur - J1. Pasirkaliki, intersection Jl. Cibaduyut - Jl. Soekarno Hatta, intersection J1. Kiaracondong - Jl. Soekarno Hatta and intersection Jl. Gede Bage - Jl. Soekarno Hatta. For the purposes of analysis and simulation, only one intersection of Jl. Cibaduyut-Jl. Soekarno-Hatta. The collection of sample data was obtained by direct survey at the study location, by measuring, enumerating and direct observation in the field. The categories of data taken include data geometric intersections, conditions of markers, intersections and legs of intersections. Traffic data including the flow of vehicles, number of vehicle queues, length of signal time, number of vehicles that stop at the Motorcycles Stop Room (MSR) and the number of vehicles blocking Left Turn On Red (LTOR) lane. The geometric intersections studied are as follows.

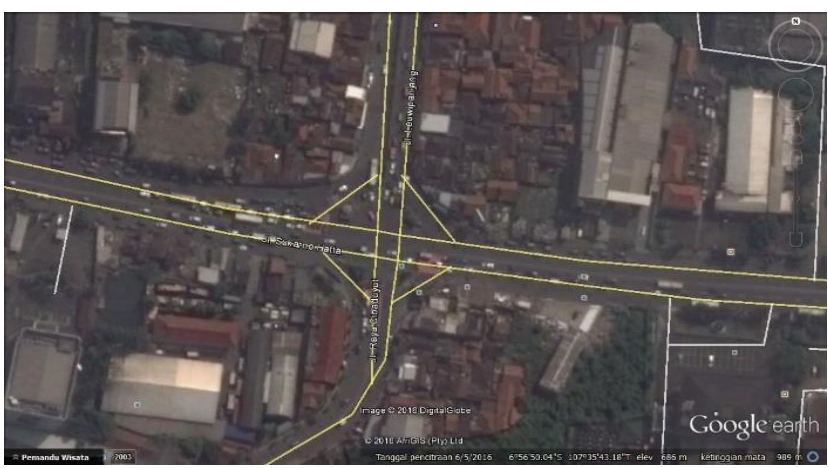

Fig. 1. Intersection of road. Cibaduyut-Soekarno Hatta with global positioning system

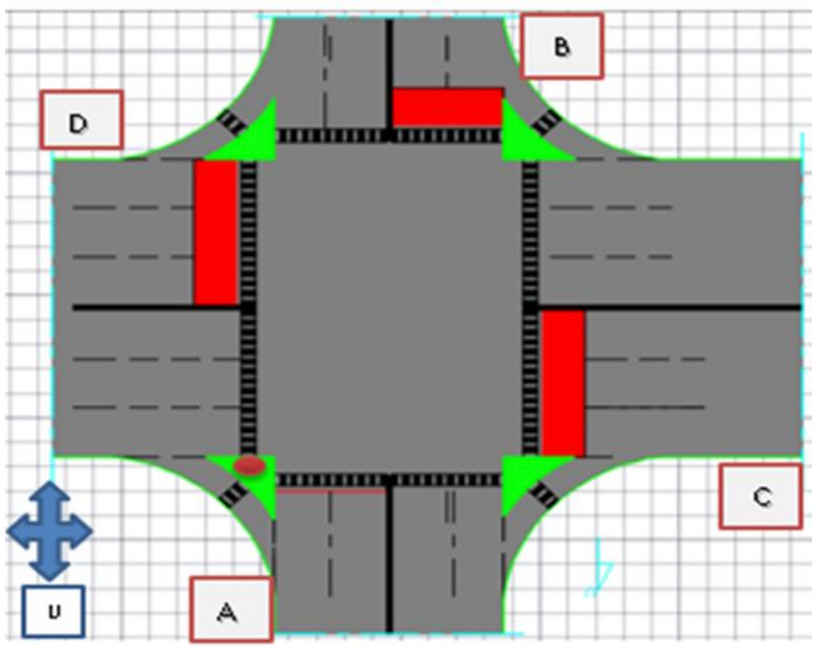

Description : The red color is MSR

D-C : Direction of Soekarno Hatta street

A-B : Direction Cibaduyut street

\subsection{Design fuzzy logic traffic light controller}

There were 4 vriables used in this experiment based on traffic flow, queue, MSR and LTOR used for the design of measuring the performance of an intersection, these variables were obtained through surveys during non peak hour conditions. Experimental variables are divided into 2 categories that is numerical variables such as traffic flow and number of queued vehicles, while linguistic variables include the number of vehicles make to violations at MSR and LTOR. All of these variables must be tested statistically by the average hypothesis testing method of standard normal distribution, in order to see the level of validity and confidence level, the obtained test value is equivalent to the membership function value in the fuzzy logic model. Test statistics through the following formula,

$$
Z=\left(x-\mu_{0}\right) /(\sigma / \sqrt{ } n)
$$

$\mathrm{x} \quad=$ average value of research results

$\mu_{0} \quad=$ existing average value

$\sigma \quad=$ value of varians

$\mathrm{n} \quad=$ number of research samples 
The test results criteria on the standard normal distribution for the two-side test with $95 \%$ confidences level.

$-\mathrm{z}_{1 / 2(1-\alpha)}<\mathrm{z}<\mathrm{z}_{1 / 2(1-\alpha)}$, the $\mathrm{z}$ value obtained is an area of acceptance of the hypothesis $\mathrm{H}_{0}$. The probability of the reception area will be equivalent to the membership function value in the fuzzy logic model. Based on de Morgan's law the best membership function value is $\mathrm{X}(\mathrm{C}) \geq 0.5$ [9], mathematically can be described as follows, When $\mathrm{C}$ is a provision, if $\mathrm{C}$ contains a complete pair of pairs, and $\mathrm{C}$ is a valid fuzzy called $\mathrm{X}(\mathrm{C})$ $\geq 0.5$ then when $\mathrm{C}=\mathrm{L}_{1} \cup \mathrm{L}_{2} \quad \ldots \ldots \ldots . . . \mathrm{L}_{\mathrm{n}}$ it is assumed that $\mathrm{Li}$ and $\mathrm{Lj}$ form a complete pair, $\mathrm{T}(\mathrm{Li})=1-\mathrm{T}(\mathrm{Lj})$ for every possible provision, one of two $\mathrm{T}(\mathrm{Li})$ or $\mathrm{T}(\mathrm{Lj})$ will be greater or equal to 0.5 therefore, $\max [\mathrm{T}(\mathrm{Li}), \mathrm{T}(\mathrm{Lj})] \geq$ 0.5 for the possible provisions then,

$\mathrm{T}(\mathrm{C})=\operatorname{maks}\left[\mathrm{T}\left(\mathrm{L}_{1}\right), \mathrm{T}\left(\mathrm{L}_{2}\right), \ldots, \mathrm{T}\left(\mathrm{L}_{\mathrm{n}}\right)\right]$

$\mathrm{T}(\mathrm{C})=\operatorname{maks}\left[\mathrm{T}\left(\mathrm{L}_{1}\right), \mathrm{T}\left(\mathrm{L}_{2}\right), . ., \mathrm{T}\left(\mathrm{L}_{\mathrm{i}}\right), . . \mathrm{T}\left(\mathrm{L}_{\mathrm{j}}\right), . ., \mathrm{T}\left(\mathrm{L}_{\mathrm{n}}\right)\right]$

$\geq \max \left[\mathrm{T}\left(\mathrm{L}_{\mathrm{i}}\right), \mathrm{T}\left(\mathrm{L}_{\mathrm{j}}\right)\right] \geq 0,5$

Then $\mathrm{C}$ is valid Fuzzy.

When the variable input has been tested and the results are quite valid based on de Morgan's theory, then entered in the fuzzy inference process which is the theoretical basis of the fuzzy set, that is the balance of a set I and an L space where each mapping I to L is called an L - Fuzzy Set .L (I) is a mapping classification all from I to element $\mathrm{fV} g$ on $\mathrm{L}(\mathrm{I})$ which is defined as the point through point [9] that is,

$(\mathrm{fVg}) \mathrm{x}=\operatorname{Lub}\{\mathrm{f}(\mathrm{x}), \mathrm{g}(\mathrm{x})\}$ for $\mathrm{L}(0,1)$

then $(\mathrm{fVg}) \mathrm{x}=\operatorname{maks}\{\mathrm{f}(\mathrm{x}), \mathrm{g}(\mathrm{x})\}$

After the fuzzification process that produces the value $\mathrm{f}_{1}, \mathrm{f}_{2} \ldots \mathrm{f}_{8}$ as fuzzy set, then determines the fuzzy inference value $\left(I_{1}, I_{2} \ldots I_{n}\right)$ using the percentage of maxor through " $U$ " notation and this is a combined process of the combination of each fuzzy inference by finding the maximum value for each $\mathrm{I}_{\mathrm{i}}$. The combination of each fuzzy inference value is $\mathrm{I}_{i}=\mathrm{m}^{\mathrm{n}}$ where $\mathrm{n}=$ number of variables

and $\mathrm{m}=2$ is a constant which is then calculated in triangular fuzzy sets [11]. Through fuzzification with membership function and fuzzy set for determining the value of the lower bound and upper limit which will produce a fuzzy inference value. In this study $\mathrm{n}=4$ and $\mathrm{m}=2$ namely $\mathrm{f}_{1}$ and $\mathrm{f}_{2}$ and then: $\mathrm{I}_{i}=\mathrm{m}^{\mathrm{n}}=2^{4}=16$ while the Fuzzy Inference (FI) formula is formulated through :

Formula FI $=\mu_{\text {rule }} \quad=\mu_{\text {FUQUD }}(\mathrm{x})$

$=\max \left[\left\{\mu_{\text {statement } 1: F}\right\},\left\{\mu_{\text {statement } 2: Q}\right\},\left\{\mu_{\text {statement } 3}: D\right\}\right]$

(4)

$=\max \left[\left\{\mu_{\mathrm{F}}(\mathrm{x}), \mu_{\mathrm{Q}}(\mathrm{x}), \mu_{\mathrm{D}}(\mathrm{x})\right\}\right]$, for all $\mu € \mathrm{x}$

$=\max \left[U f_{n}\right]$, where $f_{n}=$ fuzzy set; $n=1,2.3,4,5,6$

Ii $=\max$ [output fuzzifier], meaning that fuzzy inference starts from $\mathrm{I}_{1}, \mathrm{I}_{2} \ldots \mathrm{I}_{16}$ and the value of $\mathrm{Ii}$ is located between 0 and 1 , according to the formula of Mamdani [6]. Sign " $U$ " = indicated the percentage of max-Union between membership function values is the max-Mamdani process. Based on the theorem [9] as follows: $\chi_{(\mathrm{Si})}=\max _{\mathrm{S}} \epsilon_{\mathrm{K}} \chi_{(\mathrm{S})}$. Next the potential of the $2^{\mathrm{K}}$ set has $2^{\mathrm{n}}$ members where: $\mathrm{K}_{1}>\mathrm{K}_{2}>\ldots>\mathrm{K}_{\mathrm{i}}$, where $\mathrm{K}=$ $\mathrm{n}$ is an integer in the order of the large to small values, which will determine the Ii arrangement for the fuzzifier output function. $I_{i}$ values are arranged based on a combination of values $f_{1}, f_{2} \ldots f_{8}$ and the result is the maximum value.The combination arrangement that occurs from 4 variables namely $\mathrm{F}=$ Flow, $\mathrm{Q}=$ Queue, $\mathrm{R}$ $=\mathrm{MSR}$ and $\mathrm{L}=\mathrm{LTOR}$ with Membership Function $\mathrm{MF}=$ 3 ( $\mathrm{L}=$ Low, $\mathrm{M}=$ Medium, $\mathrm{L}=$ Large) is the number of states raised by the number of variables formulated (\#

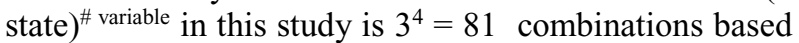
on Mamdani "Union" theory. Next is the fuzzy rule base process here, there is a limit for each variable obtained by the if-and-then concept. As an illustration when there is a queue and is very long, green time needs to be added. Rule base is the basis of the provisions for a rule that is used based on the suitability of the input data of each variable research results of field data through fuzzy curves $(0-1)$, while the output planning process that will be generated from fuzzy logic models and involves membership functions based on interval values certain. Finally, the defuzzifier process using center of average (COA) is defuzzification meaning center of average for each intersection arm in isolation, while the formulation of the model is,

$\mathrm{COA}=\left[\sum\left(\mathrm{B}_{\mathrm{i}} \mathrm{X} \mathrm{I}_{\mathrm{i}}\right)\right] / \sum \mathrm{I}_{\mathrm{i}}$

Where : $i=1,2,3 \ldots . n$. $B i=$ fuzzy rule base, $I_{i}=$ fuzzy inference engine [12].

The optimization method of signalized intersection method isolated with fuzzy logic model can be seen in the following diagram,

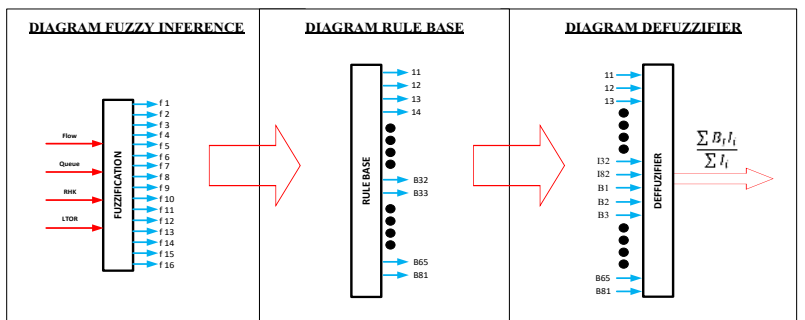

Fig. 3. Fuzzy logic design

The COA process above in principle resembles an analysis based on other fuzzy inference models, such as the use of a center of gravity (COG) model [13] as follows,

$$
C O G=\frac{\sum_{x=a}^{b} \mu_{A}(\ell x) X x \ell}{\sum_{x=a}^{b} \mu_{A}(\not x)}
$$

$W A=\frac{\mu\left(k_{1}\right) x k_{1}+\mu\left(k_{2}\right) x k_{2}+\mu\left(k_{3}\right) x k_{3}+\mu\left(k_{4}\right) x k_{4}+\mu\left(k_{5}\right) x k_{5}}{\mu\left(k_{1}\right)+\mu\left(k_{2}\right)+\mu\left(k_{3}\right)+\mu\left(k_{4}\right)+\mu\left(k_{5}\right)}$

Where:

The member value $\mu(k)$ is located between 0 and 1 based on fuzzificator the defuzzification calculation is used $\mu(k)$ and the value is related to the format of each variable.

$W A=$ Weight Average 


\subsection{Parameters constraints}

The time limit for parameter surveys is measured based on the condition of the intersection during non peak hour in the morning 9:00 to $10: 00$, noon $14.00-15.00$ and afternoon 20.00-21.00 for one hour within 15 minutes. Non peak hour survey time needs to be done because it often happens traffic violations by drivers in that time condition. The parameters obtained from the survey results are quantitative data and qualitative data that will be analyzed based on the fuzzy logic model. Input parameters of quantitative data in the form of traffic flow and the number of vehicles queued at each intersection approach, while the parameters of qualitative data in the form of linguistic variables regarding traffic behavior such as traffic violations that stop at LTOR or MSR. Another limitation is the geometric condition of the intersection that must meet several specified criteria including the existing intersection must be isolated from other intersections. The duration of the traffic light is determined by fixed or pre-time in a certain time. The measuring physical conditions such as the width of the lane for each arm, the width of the crossing lane width, including the road markings for example, available zebra cross, stop line and MSR. As well as the duration of the traffic lights for red, yellow and green, the number of phases of the vehicle passing, inter green time and cycle time. Including the classification of traffic flow includes the category of vehicle types, the pattern of direction of movement to be straight, turn left and turn right and the amount of current of vehicles passing through the intersection. In this study as an analytical material using 4 parameters, namely the amount of traffic flow, the number of queued vehicles and the number of traffic violations such as car ownership stops at MSR or direct left turn lanes (LTOR) are blocked by motor cycle or vehicles.

The data input obtained is based on the results of a survey at one of the Cibaduyut intersections - Soekarno Hatta Road and is the existing data, then an analysis of the development of fuzzy logic models for isolated intersection signals. In order to maintain the quality of the data obtained based on the results of the survey it is necessary to first test of statistically through the average standard normal distribution model. Data testing is carried out on quantitative data criteria such as traffic flow and the number of queued vehicles and qualitative data or linguistics such as four wheels violating MSR and LTOR. The effect of valid test results will improve the performance of the signalized intersection as a whole and these conditions need to be done because in the application of the fuzzy logic model must be enaugh data validity level criteria [9]. The data processing is based on fuzzy logic models, carried out for linguistic data and involves fuzzifier analysis, inference engine, rule base, defuzzifier. The finally to get conclusions obtained by the central of average method, to result output signal settings and minimizing intersection queues. Fuzzifier analysis involves membership functions as a basic plan to group data input on one of the small, medium and large classification criteria. Data from the survey were developed by means of a Fuzzy model, that is the initial data which is crisp and deterministic distributed, converted into linguistic membership functions and probabilistic distribution through fuzzy sets. Data processing was carried out using 4 variables that is traffic flow, queue, RHK and LTOR, which were obtained based on the results of the survey. In order to make it easier to process the analysis using Fuzzy Logic method, the output is signal setting. The data obtained from the survey results in this case because it uses a Fuzzy logic model, the probability value of the data input will be equivalent to the membership function in the fuzzy logic process. The numerical data input will then be processed using a fuzzy variable, namely through the membership function while output is an extended signal and reduces queue.

\section{Data analysis}

Data obtained from the experiment, upon fuzzification, is fed into Microsoft Excel, based on formula (5) above. the results of field surveys during the morning, afternoon and evening periods at the cibaduyut-soekarno Hatta intersection for more details can be seen in Table 1 below:

Table 1. Summary of queue survey result of intersection Cibaduyut - Soekarno Hatta

\begin{tabular}{|c|c|c|c|c|c|c|c|c|c|c|c|c|c|c|c|c|c|c|c|c|c|}
\hline \multirow{3}{*}{ App } & \multirow{3}{*}{$\begin{array}{c}\text { Survey } \\
\text { Period } \\
\text { (1 hour) }\end{array}$} & \multirow{3}{*}{$\begin{array}{c}\text { Flow } \\
Q \\
(\mathrm{pcu} / \mathrm{h})\end{array}$} & \multirow{3}{*}{$\begin{array}{l}\text { Wide } \\
\text { We } \\
(\mathrm{m})\end{array}$} & \multirow{3}{*}{$\begin{array}{c}\text { Green } \\
\text { G } \\
(\mathrm{sec})\end{array}$} & \multicolumn{2}{|l|}{ Signal } & \multirow{3}{*}{$\begin{array}{c}\text { Inter } \\
\text { Green } \\
\text { IG } \\
(\mathrm{sec}) \\
\end{array}$} & \multirow{3}{*}{$\begin{array}{c}\text { Cycles } \\
\text { c } \\
(\mathrm{sec})\end{array}$} & \multicolumn{2}{|c|}{ Lost Time } & \multirow{3}{*}{$\begin{array}{l}\text { Speed } \\
(\mathrm{V}) \\
(\mathrm{m} / \mathrm{s})\end{array}$} & \multirow{2}{*}{\multicolumn{2}{|c|}{ Approach }} & \multirow{3}{*}{$\begin{array}{c}\text { Headway } \\
\text { Hd } \\
(\mathrm{cm})\end{array}$} & \multirow{3}{*}{$\begin{array}{l}\text { Late } \\
\text { Fase } \\
\text { Green } \\
\text { NQ1 } \\
\text { (pcu) }\end{array}$} & \multirow{3}{*}{$\begin{array}{l}\text { Coming } \\
\text { Fase } \\
\text { Red } \\
\text { NQ2 } \\
\text { (pcu) }\end{array}$} & \multirow{3}{*}{$\begin{array}{c}\text { Queue } \\
\text { NQ } \\
\text { (pcu) }\end{array}$} & \multirow{3}{*}{$\begin{array}{l}\text { Long } \\
\text { Queue } \\
\text { QL } \\
\text { (m) } \\
\end{array}$} & \multicolumn{3}{|c|}{ Number of vehicle } \\
\hline & & & & & Amber & Red & & & \multirow{2}{*}{$\begin{array}{c}\text { Start } \\
\text { Ls } \\
(\mathrm{sec})\end{array}$} & \multirow{2}{*}{$\begin{array}{c}\text { End } \\
\text { Le } \\
(\mathrm{sec}) \\
\end{array}$} & & & & & & & & & \multirow{2}{*}{$\begin{array}{c}\text { LTOR } \\
\text { L } \\
\text { (pcu) }\end{array}$} & \multirow{2}{*}{\begin{tabular}{c|} 
Capc \\
$Q$ \\
(pcu)
\end{tabular}} & \multirow{2}{*}{$\begin{array}{c}\text { MSR } \\
\text { D } \\
(\mathrm{pcu})\end{array}$} \\
\hline & & & & & $\underset{(\mathrm{sec})}{\mathrm{A}}$ & $\underset{(\mathrm{sec})}{\mathbf{R}}$ & & & & & & $\begin{array}{c}\text { Protect } \\
\text { P }\end{array}$ & $\begin{array}{c}\text { Opposite } \\
0\end{array}$ & & & & & & & & \\
\hline \multirow{3}{*}{$\mathrm{N}$} & 9.-10. & 1416 & \multirow{3}{*}{15,5} & \multirow{3}{*}{160} & \multirow{3}{*}{2} & \multirow{3}{*}{172} & \multirow{3}{*}{5} & \multirow{3}{*}{330} & \multirow{3}{*}{2} & \multirow{3}{*}{2} & & & & & 0 & 14 & 14 & 70 & 0 & 1416 & 0 \\
\hline & $14-15$ & 1599 & & & & & & & & & 3 & $\mathbf{P}$ & & 50 & 7 & 16 & 19 & 115 & 0 & 2895 & 0 \\
\hline & $20-21$ & 1289 & & & & & & & & & & & & & 0 & 12 & 12 & 60 & 0 & 1289 & 0 \\
\hline & $9-10$ & 779 & & & & & & & & & & & & & 11 & 23 & 34 & 170 & 6 & 1042 & 6 \\
\hline $\mathrm{s}$ & $14-15$ & 701 & 8,8 & 70 & 3 & 260 & 3 & 330 & 2 & 3 & 3 & $\mathbf{P}$ & & 50 & 7 & 6 & 13 & 65 & 0 & 701 & 0 \\
\hline & $20-21$ & 750 & & & & & & & & & & & & & 10 & 6 & 16 & 80 & 0 & 750 & 0 \\
\hline & $9-10$ & 689 & & & & & & & & & & & & & 0 & 10 & 10 & 50 & 0 & 689 & 0 \\
\hline E & $14-15$ & 745 & 12,2 & 70 & 3 & 260 & 3 & 330 & 2 & 3 & 3,6 & $\mathbf{P}$ & & 50 & 4 & 10 & 14 & 70 & 0 & 745 & 0 \\
\hline & $20-21$ & 845 & & & & & & & & & & & & & 1 & 11 & 18 & 60 & 0 & 1243 & 0 \\
\hline & $9-10$ & 855 & & & & & & & & & & & & & 36 & 10 & 19 & 230 & 0 & 855 & 0 \\
\hline $\mathrm{w}$ & $14-15$ & 1351 & 15 & 30 & 2 & 302 & 3 & 330 & 2 & 2 & 3,5 & $\mathbf{P}$ & & 50 & 61 & 20 & 36 & 405 & 1 & 472 & 1 \\
\hline & $20-21$ & 1308 & & & & & & & & & & & & & 61 & 18 & 30 & 395 & 0 & 1308 & 0 \\
\hline
\end{tabular}




\section{Result and discussions}

This study we have analysis of four variables that is the amount of traffic flow, the number of vehicle queues from each direction of approach and the number of vehicles that violate the motor cycles stop room (MSR) and left turn onred (LTOR). The result of the intersection survey Cibaduyut-Soekarno Hatta can be seen in (Table 2).

Table 2. Input of survey results of existing signal intersection

\begin{tabular}{|c|c|c|c|c|c|c|c|}
\hline \multirow[b]{2}{*}{$\begin{array}{l}\text { Inters } \\
\text { ection }\end{array}$} & \multirow[b]{2}{*}{$\begin{array}{l}\text { Appr } \\
\text { oach }\end{array}$} & \multicolumn{5}{|c|}{ Traffic Variable } & \multirow[b]{2}{*}{$\begin{array}{l}\text { Degre } \\
\text { e } \\
\text { Satur } \\
\text { ation }\end{array}$} \\
\hline & & $\begin{array}{l}\text { Flow } \\
\text { (pcu/ } \\
\text { g.h) }\end{array}$ & $\begin{array}{c}\text { Queu } \\
\text { e } \\
\text { (pcu/ } \\
\text { g.h) }\end{array}$ & $\begin{array}{c}\text { MSR } \\
\text { (pcu/ } \\
\text { g.h) }\end{array}$ & $\begin{array}{c}\text { LTOR } \\
\text { (pcu/ } \\
\text { g.h) }\end{array}$ & $\begin{array}{c}\text { Capa } \\
\text { city } \\
\text { (pcu/ } \\
\text { g.h) }\end{array}$ & \\
\hline \multirow{4}{*}{ Cbyt-SH } & $\mathrm{N}$ & 1416 & 19 & 0 & 0 & 2895 & 0,49 \\
\hline & $\mathrm{s}$ & 779 & 34 & 6 & 6 & 1042 & 0,75 \\
\hline & $E$ & 689 & 18 & 0 & 0 & 1243 & 0,55 \\
\hline & W & 855 & 36 & 6 & 1 & 472 & 1,80 \\
\hline
\end{tabular}

Note : $N=$ North ; $S=$ South ; $E=$ East $; W=$ West
Clearly, traffic violations often occur from the direction of the south and west, even though the traffic flow is in normal condition but the degree of saturation is large and close to traffic jams. So it will interupted with the behavior of the driver when running the vehicle, giving rise to an impatient attitude and wanting to get to the destination which causes drivers to commit violations. For the purposes of analysis, the data obtained from the survey must first be tested through a confidence test, or in this case because it uses the Fuzzy model. The probability value will be equivalent to the membership function in the fuzzy process for more details can be seen in Table 3 below:

Table 3. Results of testing of northern approach membership

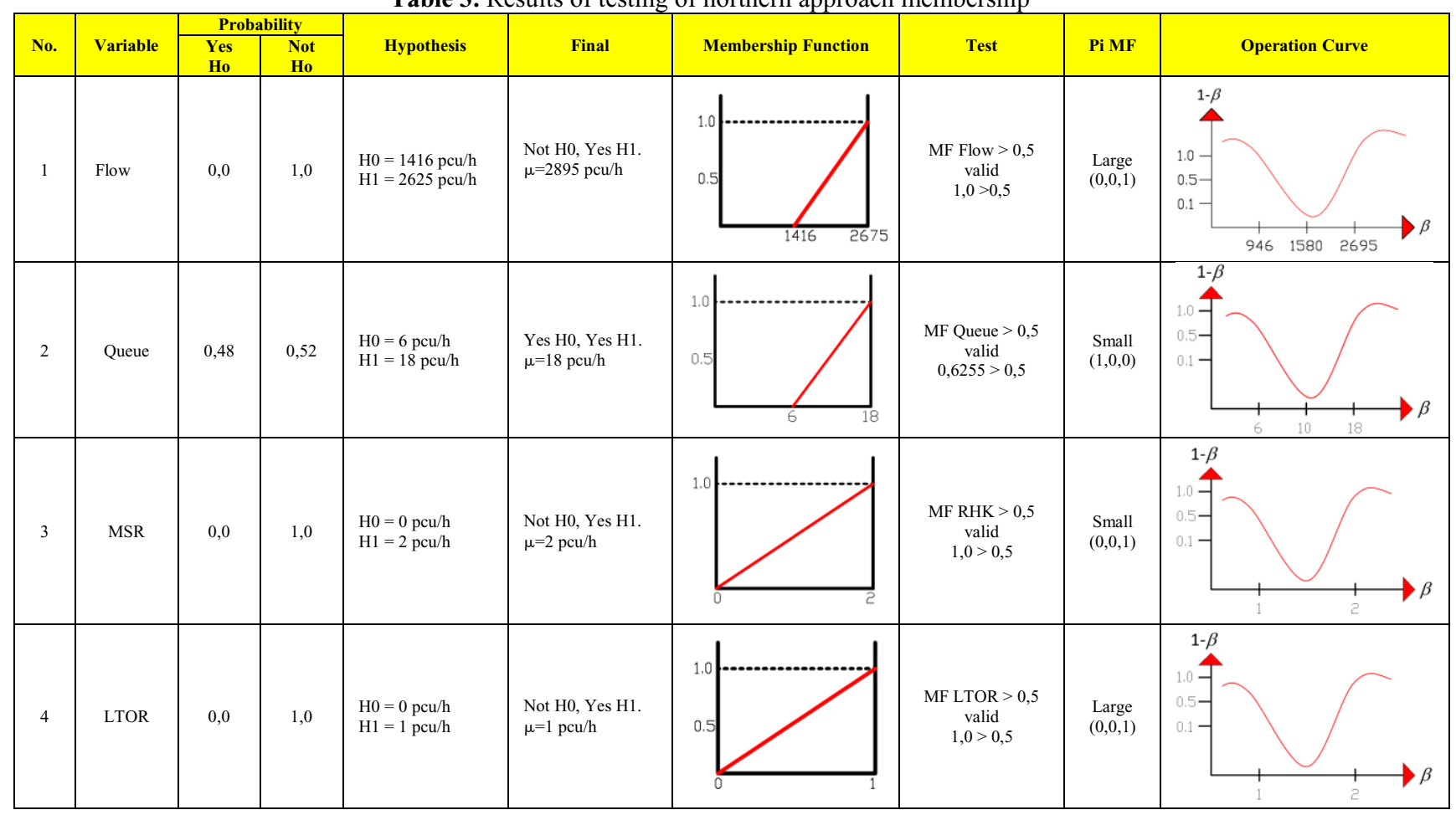

Furthermore, for the formation analysis and generate linguistic variables performed with fuzzy logic models. Through several stages of the process by fuzzifier, fuzzy inference, base rule, defuzzifier and center of average [12]. The fuzzifier process here begins to be calculated from each variable input with the lower limit and upper limit or region occupied rules, then each variable input is calculated for its fuzzy set value. The results obtained are in the form of Fuzzy Set for values $f_{1}, f_{2, \ldots \ldots . .} f_{8}$. As for the calculation process is carried out through the lower and upper limits of each region for each input variable. In this study 4 variables are used, because each traffic variable has a lower limit and upper limit. Then the Fuzzy Set value will be obtained 8 functions and this is the basis for calculation for Fuzzy Inference, for more details can be seen in table 4. below:

Table 4. Results of the north fuzzification approach

\begin{tabular}{|l|l|l|l|l|}
\hline $\begin{array}{c}\text { Variabel } \\
\text { Input }\end{array}$ & $\begin{array}{l}\text { Triangular } \\
\text { Fuzzy set }\end{array}$ & $\begin{array}{c}\text { Data } \\
\text { Input }\end{array}$ & $\begin{array}{c}\text { Region } \\
\text { Occupied }\end{array}$ & Fuzzy Set Calculation \\
\hline Flow & $\begin{array}{l}\mathrm{m} \leq \mathrm{x}<\mathrm{b} \\
(\mathrm{b}-\mathrm{x}) /(\mathrm{b}-\mathrm{m})\end{array}$ & $\begin{array}{l}\mathrm{x}=1416 \\
\mathrm{pcu} / \mathrm{g} \cdot \mathrm{h}\end{array}$ & $\begin{array}{l}1000 \leq \mathrm{x} \\
<2000 \\
\text { Region } 2\end{array}$ & $\begin{array}{l}\mathrm{f}_{1}=(2000-1416) / 1000= \\
0,6 \\
\mathrm{f}_{2}=1-\mathrm{f}_{1}=1-0,6=0,4\end{array}$ \\
\hline Queue & $\begin{array}{l}\mathrm{m} \leq \mathrm{x}<\mathrm{b} \\
(\mathrm{b}-\mathrm{x}) /(\mathrm{b}-\mathrm{m})\end{array}$ & $\begin{array}{l}\mathrm{x}=6 \\
\mathrm{pcu} / \mathrm{g} \cdot \mathrm{h}\end{array}$ & $\begin{array}{l}0 \leq \mathrm{x}< \\
10 \\
\text { Region } 1\end{array}$ & $\begin{array}{l}\mathrm{f}_{3}=(10-6) / 10=0,4 \\
\mathrm{f}_{4}=1-\mathrm{f}_{3}=1-0,4=0,6\end{array}$ \\
\hline MSR & $\begin{array}{l}\mathrm{m} \leq \mathrm{x}<\mathrm{b} \\
(\mathrm{b}-\mathrm{x}) /(\mathrm{b}-\mathrm{m})\end{array}$ & $\begin{array}{l}\mathrm{x}=0 \\
\text { pcu/g.h }\end{array}$ & $\begin{array}{l}0 \leq \mathrm{x}<3 \\
\text { Region } 1\end{array}$ & $\begin{array}{l}\mathrm{f}_{3}=(3-0) / 3=1,0 \\
\mathrm{f}_{4}=1-\mathrm{f}_{3}=1-1=0,0\end{array}$ \\
\hline LTOR & $\begin{array}{l}\mathrm{m} \leq \mathrm{x}<\mathrm{b} \\
(\mathrm{b}-\mathrm{x}) /(\mathrm{b}-\mathrm{m})\end{array}$ & $\begin{array}{l}\mathrm{x}=0 \\
\text { pcu/g.h }\end{array}$ & $\begin{array}{l}0 \leq \mathrm{x}<3 \\
\text { Region } 1\end{array}$ & $\begin{array}{l}\mathrm{f}_{5}=(3-0) / 3=1,0 \\
\mathrm{f}_{6}=1-\mathrm{f}_{5}=1-1=0,0\end{array}$ \\
\hline
\end{tabular}


Based on the same method as table 3, the results of fuzzification will be obtained for each approach in the direction of South, East and West. Membership functions for each variable can be arranged like this:

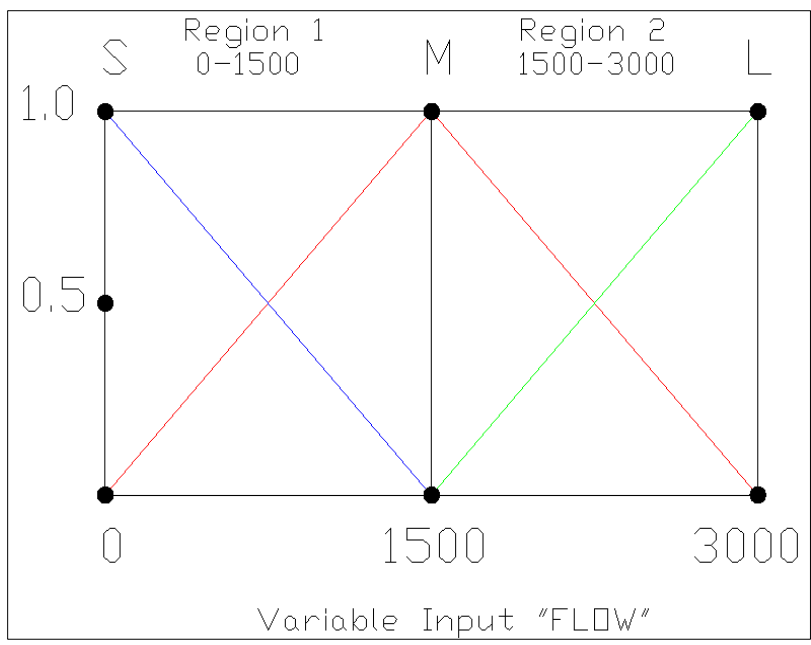

Fig. 4. Membership function input variabel "Flow"

In the same way, membership functions for other variabels will be obtained. The composition of the combinations that occur from 4 variables that is $\mathrm{F}=$ Flow, $\mathrm{Q}=$ Queue, $\mathrm{D}=\mathrm{MSR}$ and $\mathrm{T}=\mathrm{LTOR}$ with Membership Function $\mathrm{MF}=3(\mathrm{~L}=$ Low, $\mathrm{M}=$ Medium, $\mathrm{L}=$ Large $)$ is the number of states raised by the number of variables formulated (\# state) ${ }^{\#}$ variable [14], in this study $3^{4}=81$ combinations of "Union". The composition of fuzzy inference arrangement is $2^{\mathrm{n}}=2^{4}=16$, see table 5 below:

Table 5. Fuzzy inference value

\begin{tabular}{|c|c|c|c|c|}
\hline No & $\mathbf{I i}$ & $\begin{array}{c}\text { Output } \\
\text { Fuzzifier }\end{array}$ & Fuzzy Set Value & $\begin{array}{c}\text { Max Ii } \\
\text { Value }\end{array}$ \\
\hline 1 & $\mathrm{I}_{1}$ & $=\mathrm{f}_{1} \cup \mathrm{f}_{3} \cup \mathrm{f}_{5} \cup \mathrm{f}_{7}$ & $=0,5 \cup 0,6 \cup 0,7 \cup 0,3$ & 0,7 \\
\hline 2 & $\mathrm{I}_{2}$ & $=\mathrm{f}_{1} \cup \mathrm{f}_{3} \cup \mathrm{f}_{5} \cup \mathrm{f}_{8}$ & $=0,5 \cup 0,6 \cup 0,7 \cup 0,7$ & 0,7 \\
\hline 3 & $\mathrm{I}_{3}$ & $=\mathrm{f}_{1} \cup \mathrm{f}_{3} \cup \mathrm{f}_{6} \cup \mathrm{f}_{7}$ & $=0,5 \cup 0,6 \cup 0,3 \cup 0,3$ & 0,6 \\
\hline 4 & $\mathrm{I}_{4}$ & $=\mathrm{f}_{1} \cup \mathrm{f}_{3} \cup \mathrm{f}_{6} \cup \mathrm{f}_{8}$ & $=0,5 \cup 0,6 \cup 0,3 \cup 0,7$ & 0,7 \\
\hline 5 & $\mathrm{I}_{5}$ & $=\mathrm{f}_{1} \cup \mathrm{f}_{4} \cup \mathrm{f}_{5} \cup \mathrm{f}_{7}$ & $=0,5 \cup 0,4 \cup 0,7 \cup 0,3$ & 0,7 \\
\hline 6 & $\mathrm{I}_{6}$ & $=\mathrm{f}_{1} \cup \mathrm{f}_{4} \cup \mathrm{f}_{5} \cup \mathrm{f}_{8}$ & $=0,5 \cup 0,4 \cup 0,7 \cup 0,7$ & 0,7 \\
\hline 7 & $\mathrm{I}_{7}$ & $=\mathrm{f}_{1} \cup \mathrm{f}_{4} \cup \mathrm{f}_{6} \cup \mathrm{f}_{7}$ & $=0,5 \cup 0,4 \cup 0,3 \cup 0,3$ & 0,5 \\
\hline 8 & $\mathrm{I}_{8}$ & $=\mathrm{f}_{1} \cup \mathrm{f}_{4} \cup \mathrm{f}_{6} \cup \mathrm{f}_{8}$ & $=0,5 \cup 0,4 \cup 0,3 \cup 0,7$ & 0,7 \\
\hline 9 & $\mathrm{I}_{9}$ & $=\mathrm{f}_{2} \cup \mathrm{f}_{3} \cup \mathrm{f}_{5} \cup \mathrm{f}_{7}$ & $=0,5 \cup 0,6 \cup 0,7 \cup 0,3$ & 0,7 \\
\hline 10 & $\mathrm{I}_{10}$ & $=\mathrm{f}_{2} \cup \mathrm{f}_{3} \cup \mathrm{f}_{5} \cup \mathrm{f}_{8}$ & $=0,5 \cup 0,6 \cup 0,7 \cup 0,7$ & 0,7 \\
\hline 11 & $\mathrm{I}_{11}$ & $=\mathrm{f}_{2} \cup \mathrm{f}_{3} \cup \mathrm{f}_{6} \cup \mathrm{f}_{7}$ & $=0,5 \cup 0,6 \cup 0,3 \cup 0,3$ & 0,6 \\
\hline 12 & $\mathrm{I}_{12}$ & $=\mathrm{f}_{2} \cup \mathrm{f}_{3} \cup \mathrm{f}_{6} \cup \mathrm{f}_{8}$ & $=0,5 \cup 0,6 \cup 0,3 \cup 0,7$ & 0,7 \\
\hline $\mathbf{N o}$ & $\mathrm{Ii}_{1}$ & $\mathbf{O u t p u t}_{\text {Fuzzifier }}$ & Fuzzy Set $\mathbf{V a l u e}$ & $\begin{array}{c}\text { Max Ii } \\
\text { Value }\end{array}$ \\
\hline 13 & $\mathrm{I}_{13}$ & $=\mathrm{f}_{2} \cup \mathrm{f}_{4} \cup \mathrm{f}_{5} \cup \mathrm{f}_{7}$ & $=0,5 \cup 0,4 \cup 0,7 \cup 0,3$ & 0,7 \\
\hline 14 & $\mathrm{I}_{14}$ & $=\mathrm{f}_{2} \cup \mathrm{f}_{4} \cup \mathrm{f}_{5} \cup \mathrm{f}_{8}$ & $=0,5 \cup 0,4 \cup 0,7 \cup 0,7$ & 0,7 \\
\hline 15 & $\mathrm{I}_{15}$ & $=\mathrm{f}_{2} \cup \mathrm{f}_{4} \cup \mathrm{f}_{5} \cup \mathrm{f}_{7}$ & $=0,5 \cup 0,4 \cup 0,3 \cup 0,3$ & 0,5 \\
\hline 16 & $\mathrm{I}_{16}$ & $=\mathrm{f}_{2} \cup \mathrm{f}_{4} \cup \mathrm{f}_{6} \cup \mathrm{f}_{8}$ & $=0,5 \cup 0,4 \cup 0,3 \cup 0,7$ & 0,7 \\
\hline
\end{tabular}

According to Kandel, the $2^{K}$ set has $2^{n}$ members where: $K_{l}>K_{2}>\ldots>K_{i}$, and $K=n$, so if $n=4$ then the sequence composition of the fuzzy inference value is $2^{3}$ $=8$, see the fuzzifier output column for each $f_{1}$ and $f_{2}$ values there are 8 pieces, if $n=2$ then $2^{2}=4$ for $f_{3}$ and $f_{4}$, if $n=1$ then $2^{1}=2$ for $f_{5}$ and $f_{6}$, if $n=0$ then $2^{0}=1$ for $f_{7}$ and $f_{8}$, so it will fulfill rule $2^{3}>2^{2}>2^{1}>2^{0}$. [9]. After obtaining the fuzzy inference $\left(I_{1}, I_{2} \ldots, I_{16}\right)$, the calculate Rule Base $\left(B_{1}, B_{2} \ldots, B_{16}\right)$ is obtained based on the relevance of the field data from the fuzzy curve $0-1$. To find out the basic rule base this, is obtained according to the standard rules on traffic [1] and adjusted to the field conditions, then converted into fuzzy degree membership levels. In this study rule base $\left(B_{i}\right)$ application model rules are divided into 2 groups namely signal rules and Variable rules. Variable compilation and signals are each classified at $50 \%$ for small and large values. The rule base $\left(B_{i}\right)$ value is based on Mamdani's theory [14] that is, $B_{i}=$ $m^{n}$; where $m=$ the boundary of the interval class and $n$ $=$ the number of variables, so $B_{i}=m^{n}=2^{4}=16$, , so $B_{l}$, $B_{2} \ldots, B_{16}$ where; $i=1,2, \ldots \ldots .16$. The rules of the application model rule base is assumed to be the same for each intersection approach that is $50 \%$ maximum value and $50 \%$ minimum value of rule base arrangement, because the queue, MSR and LTOR variables are relatively not much different, for the rule base results can be seen in table 6 below :

Table 6. Rule of structure application rule base model

\begin{tabular}{|c|c|c|c|c|c|c|c|c|}
\hline No & \multicolumn{3}{|c|}{ TRAFFIC LIGHT } & \multicolumn{4}{|c|}{ VARIABLE TOTAL } & \multirow{2}{*}{$\mathbf{B}_{\mathbf{I}}$} \\
\hline (i) & G & $\mathbf{r}$ & $\mathbf{A}$ & FLOW & QUEUE & MSR & LTOR & \\
\hline 1 & $\mathbf{M}=\mathbf{0 , 5}$ & 0,5 & 0,2 & MEDIUM & $M=0,5$ & $M=0,4$ & $M=\mathbf{0 , 4}$ & $B_{1}$ \\
\hline 2 & $M=0,5$ & 0,5 & 0,2 & MEDIUM & $M=0,5$ & $M=0,4$ & $M=\mathbf{0 , 4}$ & $\mathrm{B}_{2}$ \\
\hline 3 & $\mathbf{M}=\mathbf{0 , 5}$ & 0,5 & 0,2 & MEDIUM & $M=0,5$ & $M=0,4$ & $M=0,4$ & $B_{3}$ \\
\hline 4 & $M=0,5$ & 0,5 & 0,2 & MEDIUM & $M=0,5$ & $M=0,4$ & $M=0,4$ & $\mathrm{~B}_{4}$ \\
\hline 5 & $M=0,5$ & 0,5 & 0,2 & MEDIUM & $M=0,5$ & $M=0,4$ & $M=\mathbf{0 , 4}$ & $B_{5}$ \\
\hline 6 & $\mathbf{M}=\mathbf{0 , 5}$ & 0,5 & 0,2 & MEDIUM & $M=0,5$ & $M=0,4$ & $M=0,4$ & $\mathrm{~B}_{6}$ \\
\hline 7 & $\mathbf{M}=\mathbf{0 , 5}$ & 0,5 & 0,2 & MEDIUM & $\mathbf{M}=\mathbf{0 , 5}$ & $M=0,4$ & $M=\mathbf{0 , 4}$ & $B_{7}$ \\
\hline 8 & $M=0,5$ & 0,5 & 0,2 & MEDIUM & $M=0,5$ & $M=0,4$ & $M=\mathbf{0 , 4}$ & $\mathrm{B}_{8}$ \\
\hline 9 & $L=1$ & 1 & 0,4 & LARGE & $L=0,6$ & $\mathbf{L}=\mathbf{0 , 7}$ & $\mathbf{L}=\mathbf{0 , 7}$ & $\mathrm{B}_{9}$ \\
\hline 10 & $L=1$ & 1 & 0,4 & LARGE & $L=0,6$ & $\mathbf{L}=\mathbf{0 , 7}$ & $\mathbf{L}=\mathbf{0 , 7}$ & $B_{10}$ \\
\hline 11 & $L=1$ & 1 & 0,4 & LARGE & $L=0,6$ & $\mathbf{L}=\mathbf{0 , 7}$ & $\mathbf{L}=\mathbf{0 , 7}$ & $B_{11}$ \\
\hline 12 & $L=1$ & 1 & 0,4 & LARGE & $L=0,6$ & $\mathbf{L}=\mathbf{0 , 7}$ & $\mathbf{L}=\mathbf{0 , 7}$ & $B_{12}$ \\
\hline 13 & $L=1$ & 1 & 0,4 & LARGE & $L=0,6$ & $\mathbf{L}=\mathbf{0 , 7}$ & $\mathbf{L}=\mathbf{0 , 7}$ & $B_{13}$ \\
\hline 14 & $L=1$ & 1 & 0,4 & LARGE & $L=0,6$ & $\mathbf{L}=\mathbf{0 , 7}$ & $\mathbf{L}=\mathbf{0 , 7}$ & $B_{14}$ \\
\hline 15 & $L=1$ & 1 & 0,4 & LARGE & $L=0,6$ & $\mathbf{L}=\mathbf{0 , 7}$ & $\mathbf{L}=\mathbf{0 , 7}$ & $B_{15}$ \\
\hline 16 & $L=1$ & 1 & 0,4 & LARGE & $L=0,6$ & $\mathrm{~L}=\mathbf{0 , 7}$ & $\mathbf{L}=\mathbf{0 , 7}$ & $B_{16}$ \\
\hline
\end{tabular}

The final result in the form of tabulation of the value of additional green time model analysis on each approach of the Cibaduyut-Soekarno Hatta intersection is as follow

Table 7. Percentage recapitulation additional green of fuzzy logic models analysis at Cibaduyut-Soekarno Hatta intersection

\begin{tabular}{|c|c|c|c|c|}
\hline Approach & Phase & $\begin{array}{c}\text { Existing } \\
\text { Green } \\
\text { Time (sec) }\end{array}$ & $\begin{array}{c}\text { Fuzzy } \\
\text { Green } \\
\text { (sec) }\end{array}$ & $\begin{array}{c}\text { Addition Average } \\
\text { every Phase }\end{array}$ \\
\hline North & 1 & 85 & 132 & 55 \\
\hline South & 2 & 178 & 276 & 55 \\
\hline East & 3 & 95 & 147 & 55 \\
\hline West & 4 & 51 & 79 & 55 \\
\hline
\end{tabular}




\section{Conclusions}

The results of the analysis show that overall the performance of signalized intersections increased significantly for each intersection aproach because there was an average increase in green time in the mount of 55\% of the existing condition. The addition of green time will obviously have an impact on the size of various variables, such as the amount of traffic in the north approaching capacity will increase from 1416 pcu / g.h the existing condition becomes 2195 pcu / g.h based on fuzzy development, as well as for other approaches. The queue of vehicles will be much reduced where there are $19 \mathrm{pcu} /$ g.h of vehicles at existing become $8 \mathrm{pcu} / \mathrm{g}$.h after fuzzy development. While for traffic violations, that is the MSR and LTOR variables may not even occur because the numbers are relatively small. It is clearly seen that there is a fundamental difference when it time comes to green light, from the "existing" condition with the development of the "Fuzzy" theory, namely the final result shows that the fuzzy model has given an increase in performance at signalized intersections based on changes in time green light.

This research is part of the research of the Bandung Institute of Technology, Doctoral Program in Transport, made possible by BPPDN Scholarship, Ministry of Research-Technology and Higher Education, Republic of Indonesia. I wish to thank student of Bandung State Polytechnic and Bandung Institute of Technology for the help in the survey.

\section{References}

1. Indonesia road capacity manual, Direktorat Umum Bina Marga, PT Bina Karya Persero (1997)

2. Kam-Wing Li, Two phase fuzzy control, Graduate Department of Electrical and Computer Engineering, University of Toronto (1996)

3. M. J. Stanojevic, Simulation analysis of isolated intersection operation, IJRRCS, Faculty of Transport and Traffic Engineering, Belgrade, Serbia (2011)

4. Y. Wenchen, et al., Adaptive two-stage fuzzy logic controller for urban traffic signals at isolated intersections, School of Transportation Engineering, TongjiUniversity, Shanghai China (2012)

5. A. Muhammad, K. Saleem M, A. Nasir, and F. Syed, Fuzzy logic based autonomous traffic control system, Sensors and Transducer vol 136 pp 132-136, Pakistan (2012)

6. Highway Capacity Manual, Transport Research Board, Washington, DC (2000)

7. M. Salehi, I. Spahvane, M. Yarahmadi, TLCSBFL : A Traffic Light Control System Base on Fuzzy Logic, International Journal of U-and-Service and Technology, Ijunesst, Iran (2014)

8. S. Mehan, Introduction of traffic light controller with fuzzy control system, IJECT vol 2, issue 3, sept 2011, Punjab, India (2011)

9. A. Kandel, 1986, Fuzzy mathematical techniques with applications, Florida State University, AddisonWesley Publishing Company (1986)
10. Y. Dexin, T. Xiujuan, X. Xue, and G. Shutao, Signal timing optimization based on fuzzy compromise programming for isolated signalized intersection, Hindawi Publishing corporation mathematical Problem in Engineering, vol. 2016, Article ID 1682394, 12 page, laboratory of Road Traffic, College of transportation, Jilin University, Changchun 130022, China (2016)

11. W. Pedrycz, F. Gomide, Fuzzy system engineering, Toward Human-Centric Computing, John Wiley and Sons, Publication (2007)

12. S. Mehta, Fuzzy control system for controlling traffic light, Proceedings of the International Multi Conference of Engineers and Computer Sciencies, Vol 1 (2008)

13. A. Alper, U. Erkam and O. Tansel, A real time traffic simulator utilizing on adaptive fuzzy inference mechanism by tuning fuzzy parameter, Springer Science Business Media (2011)

14. Mamdani, E.H, 1977, Applications of fuzzy set theory to control systems a survey, In Gupta, Saridis and Gaines (1977) 